\title{
STUDI PENGARUH KUALITAS PRODUK, KUALITAS PELAYANAN DAN HARGA TERHADAP KEPUASAN PELANGGAN PT. CITRA NUSA INSAN CEMERLANG (CNI) UNTUK KATEGORI PRODUK FOOD
}

\author{
Nita Felicia \\ Program Studi Magister Manajemen Universitas Tarumanagara \\ nitafelicia@gmail.com
}

\begin{abstract}
The rapid development of communication technologies in the future would give the negative impact to the concept of multi level marketing (MLM). Customers can easily purchase products in the online store by using their gadgets. In order to maintain company performance and optimum competitive advantage, the company should be able to understand customers' behavior. This research aims to find out the effect of product quality, service quality and price on customer satisfaction, study case in the company of PT Citra Nusa Insan Cemerlang (CNI) as MLM company, particularly in food product category. The study was conducted by distributing questionnaire with 5 point of likert scale towards 171 respondents. The criteria for the respondents were must be member of CNI, know the variation of the food product of CNI and do purchase the food product of CNI within latest 3 months. The data were analyzed by using the Statistical Package for Social Sciences (SPSS) statistical software, version 24.0. The conclusion of this research is that product quality, service quality and price, for both partially and simultaneously, have a significant and positive effect on customer satisfaction. The effect of product quality, service quality and price on customer satisfaction respectively are 0,543 , 0,359 and 0,411 .
\end{abstract}

Abstrak : Pesatnya perkembangan teknologi komunikasi di masa depan akan memberikan dampak negatif untuk konsep pemasaran multi level (MLM). Pelanggan dapat dengan mudah membeli produk di toko online dengan menggunakan gadget mereka. Untuk mempertahankan kinerja perusahaan dan keunggulan kompetitif yang optimal, perusahaan sebaiknya mampu memahami perilaku pelanggan. Penelitian ini bertujuan untuk mengetahui pengaruh dari kualitas produk, kualitas pelayanan dan harga terhadap kepuasan pelanggan, studi kasus di PT Citra Nusa Insan Cemerlang (CNI) sebagai perusahaan MLM, khususnya di kategori produk makanan. Studi ini dilakukan dengan mendistribusikan kuesioner dengan 5 skala likert kepada 171 responden. Kriteria responden adalah harus merupakan anggota CNI, mengetahui variasi produk makanan dari CNI dan melakukan pembelian produk makanan dari CNI dalam 3 bulan terakhir. Data tersebut dianalisis menggunakan statistic paket untuk ilmu sosial (SPSS) perangkat lunak statistic, versi 24.0. Kesimpulan dari hasil penelitian ini adalah kualitas produk, kualitas pelayanan dan harga, untuk secara parsial dan secara bersamaan, berpengaruh signifikan dan positif terhadap kepuasan pelanggan. Pengaruh kualitas produk, kualitas pelayanan dan harga terhadap kepuasan pelanggan secara berurutan adalah sebesar 0,543, 0,359 dan 0,411 .

Keywords : Costumer Satisfaction, Product Quality, Service Quality, Price

\section{PENDAHULUAN}

Pada era globalisasi ini, pertumbuhan bisnis MLM (Multi-Level Marketing) sangat pesat. Berdasarkan World Federation of Direct Selling (WFDSA) (2017), pasar Asia Pasifik adalah penyumbang terbesar total omset bisnis penjualan langsung (Multi-Level Marketing / MLM) dunia sebesar 46\%, disusul dengan Amerika sebesar 33\%, Eropa sebesar 20\% dan Afrika Timur Tengah sebesar $1 \%$. Di sisi lain, pesatnya perkembangan teknologi komunikasi di era globalisasi juga menggerus keberadaan bisnis MLM. Pelanggan dengan mudahnya dapat 
membeli produk di toko online melalui gadget. Untuk dapat mempertahankan kelangsungan usaha, mengembangkan perusahaan dan memperoleh laba optimal di tengah persaingan, perusahaan harus dapat memahami perilaku pelanggan. Dengan memahami perilaku pelanggan, perusahaan dapat memenuhi kebutuhan pelanggan, menciptakan kepuasan pelanggan. Untuk dapat memberikan kepuasan terhadap pelanggan, perusahaan harus dapat menjual barang atau jasa dengan kualitas yang paling baik dan dengan harga yang sesuai dengan apa yang didapatkan. Di samping itu sistem penjualan MLM yang melibatkan agen distribusi menyebabkan kualitas pelayanan juga menjadi faktor penting yang menentukan kepuasan pelanggan.

Pada penelitian ini akan dilakukan analisis adanya pengaruh kualitas produk, kualitas pelayanan dan harga terhadap kepuasan pelanggan dalam lingkup perusahaan dengan strategi pemasaran berjenjang atau Multi-Level Marketing (MLM). Perusahaan dengan strategi pemasaran berjenjang yang akan diteliti adalah PT Citra Nusa Insan Cemerlang - Indonesia (Asia), secara khusus pada kategori produk food. Penelitian ini dilakukan dengan judul penelitian, "Studi Pengaruh Kualitas Produk, Kualitas Pelayanan dan Harga terhadap Kepuasan Pelanggan PT. Citra Nusa Insan Cemerlang (CNI) untuk Kategori Produk Food."

\section{TINJAUAN PUSTAKA}

\section{Strategi Pemasaran Berjenjang atau Multi-Level Marketing}

Multi Level Marketing merupakan suatu metode menjual barang secara langsung kepada pelanggan melalui jaringan yang dikembangkan oleh para distributor yang memperkenalkan para distributor berikutnya (Axinantio, 1996). Istilah lain yang digunakan untuk multi-level marketing (MLM) adalah penjualan piramida, pemasaran jaringan dan pemasaran berantai. Strategi pemasaran ini melibatkan banyak level / tingkatan yang dikenal dengan upline / tingkat atas dan downline / tingkat bawah. (Roller, 1995).

\section{Kepuasan Pelanggan}

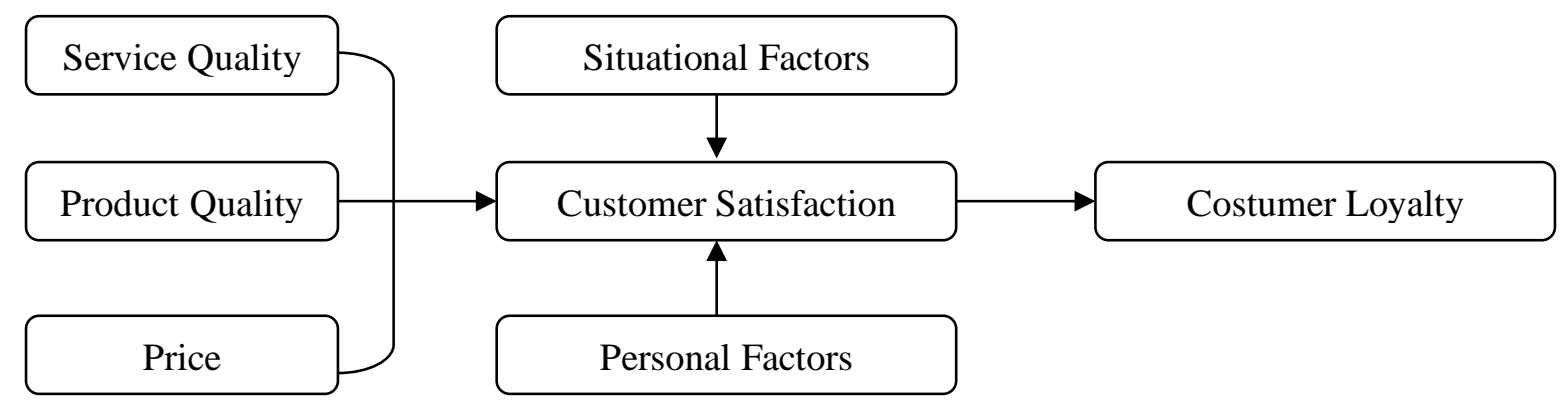

\section{Gambar 1 \\ Faktor-Faktor yang Mempengaruhi Kepuasan Pelanggan}

Sumber : Zeithaml et al. (2009)

Secara umum, kepuasan adalah perasaan senang atau kecewa yang dirasakan oleh seseorang dari hasil membandingkan kinerja produk / jasa (performance) dengan harapan terhadap produk / jasa tersebut (Kotler and Keller, 2016). Faktor-faktor yang mempengaruhi kepuasan pelanggan adalah service quality / kualitas pelayanan, product quality / kualitas produk, price / harga, situational factors / faktor situasi dan personal factors / faktor pribadi (Gambar 1) (Zeithaml et al., 2009). Kualitas pelayanan, kualitas produk dan harga dapat dikendalikan oleh perusahaan, sedangkan dua faktor lainnya merupakan faktor-faktor lain yang tidak dapat dikendalikan oleh perusahaan. 


\section{Kualitas Produk}

Menurut Kotler dan Keller (2016), kualitas produk adalah totalitas fitur dan karakteristik produk atau jasa yang bergantung pada kemampuannya untuk memuaskan kebutuhan yang dinyatakan atau tersirat. Pelanggan akan membeli suatu produk apabila merasa cocok, karena itu pembuatan produk harus disesuaikan dengan keinginan ataupun kebutuhan pelanggan agar pemasaran produk berhasil.

\section{Kualitas Pelayanan}

Kualitas pelayanan adalah mutu pelayanan yang diberikan kepada pelanggan berdasarkan standar prosedur pelayanan. Pada penerapannya ditemukan celah atau kesenjangan yang membuat penting untuk memikirkan bagaimana untuk mencapai tingkat kepuasan optimal dalam hal kualitas pelayanan (Mudie dan Pirrie, 2006).

Kunci untuk mengatasi kesenjangan ini adalah identifikasi item pengukuran kualitas pelayanan baik dari perspektif manajemen maupun dari perspektif pelanggan, menyoroti / highlighting faktor kesenjangan antara pelanggan dan penyedia pelayanan dengan mengacu pada kinerja dan ekspektasi pelanggan, dan memahami dampak yang ditimbulkan pada manajemen dalam upaya penutupan celah / kesenjangan kualitas pelayanan (Mudie dan Pirrie, 2006).

\section{Harga}

Menurut Kotler dan Amstrong (2008), harga adalah sejumlah uang yang ditagihkan atas sesuatu produk atau jasa atau jumlah dari nilai yang ditukarkan para pelanggan untuk memperoleh manfaat dari memiliki atau menggunakan suatu produk atau jasa. Jika harga suatu produk tinggi, maka pada umumnya pelanggan mengharapkan kualitas yang tinggi pula. Sebaliknya jika harga terlalu rendah, pelanggan dapat meragukan kualitas dari produk tersebut.

\section{Gambaran Umum Perusahaan - Objek Penelitian}

Secara umum terdapat 5 kategori produk PT CNI yaitu suplemen (pharmaceutical), makanan dan minuman (food), personal care \& kosmetik, peralatan rumah tangga (household), dan pertanian \& perikanan (farming) (CNI Indonesia, no year). Pada penelitian ini cakupan produk terbatas pada lingkup kategori produk food. Produk-produk yang termasuk dalam kategori produk food adalah CNI Ginseng Coffee, CNI Ginseng Coffee KUATTT, Up Coffee Sugar Free, Up Ginseng Tea, Up Green Tea, Up Honey Lemon Tea, Up Hot Dark Chocolate, Up Soya dan CNI Sehati Hifiber Pudding Cokelat.

\section{PENELITIAN TERDAHULU}

Penelitian terdahulu dilakukan oleh Iglesias dan Guillen (2004) berjudul "Perceived quality and price: their impact on the satisfaction of restaurant customers". Hasil dari penelitian ini adalah kualitas memiliki pengaruh langsung yang positif terhadap kepuasan pelanggan, sedangkan harga tidak mempengaruhi kepuasan.

Penelitian terdahulu dilakukan oleh Budiastari, S. (2016) dengan judul "The Influence of Product Quality, Price Perception and Brand Image on Satisfaction and Customer Loyalty Holcim Concrete Readymix in Jakarta". Hasil penelitian menyatakan bahwa kualitas produk tidak berpengaruh terhadap kepuasan pelanggan, sedangkan persepsi harga berpengaruh positif dan signifikan terhadap kepuasan pelanggan.

Penelitian terdahulu dilakukan oleh Farooq et al. (2018) dengan judul "Impact of service quality on customer satisfaction in Malaysia airlines: A PLS-SEM approach". Berdasarkan penelitian ini, semua dimensi kualitas pelayanan memiliki pengaruh positif, langsung dan signifikan terhadap kepuasan pelanggan. 


\section{KERANGKA PEMIKIRAN}

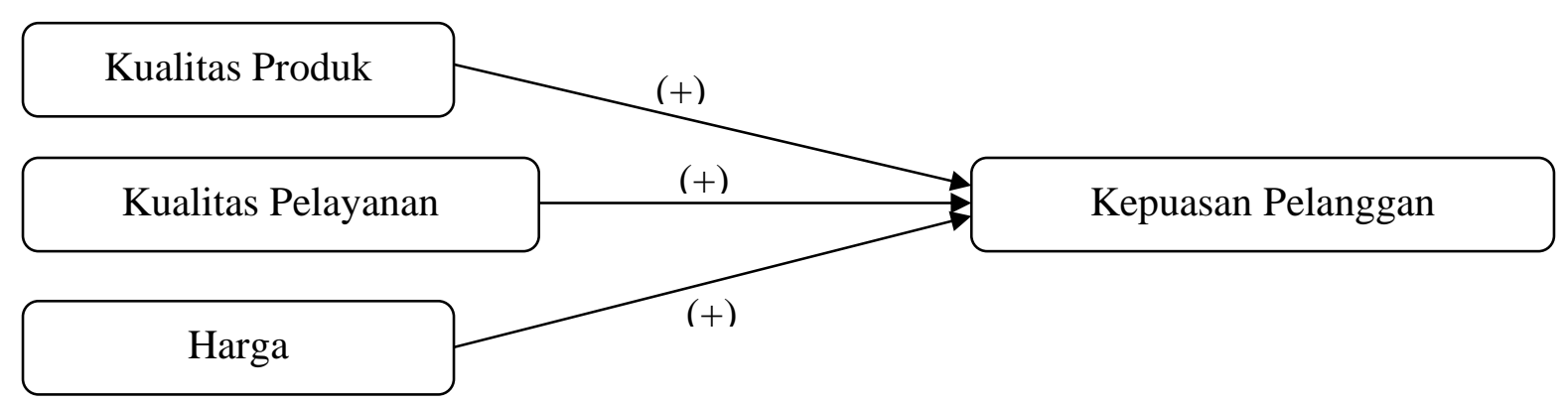

Gambar 2

Model Penelitian

\section{HIPOTESIS PENELITIAN}

H1 = Kualitas produk berpengaruh positif secara langsung dan signifikan terhadap kepuasan pelanggan PT. Citra Nusa Insan Cemerlang untuk kategori produk food

$\mathrm{H} 2$ = Kualitas pelayanan berpengaruh positif secara langsung dan signifikan terhadap kepuasan pelanggan PT. Citra Nusa Insan Cemerlang untuk kategori produk food

H3 = Harga produk berpengaruh positif secara langsung dan signifikan terhadap kepuasan pelanggan PT. Citra Nusa Insan Cemerlang untuk kategori produk food

\section{METODE PENELITIAN}

Penelitian dilakukan dengan penyebaran kuesioner kepada anggota / member dari perusahaan Multi-Level Marketing PT Citra Nusa Insan Cemerlang - Indonesia yang pernah membeli kategori produk food. Adapun penentuan populasi berdasarkan kriteria sebagai berikut: (a) mengetahui variasi produk food PT Citra Nusa Insan Cemerlang, (b) melakukan pembelian terhadap produk food PT Citra Nusa Insan Cemerlang dalam 3 (tiga) bulan terakhir

Kuesioner yang digunakan dalam penelitian ini disusun dengan format skala likert dengan skala 1-5 sebagai berikut : (1) : Sangat Tidak Setuju (STS), (2) : Tidak Setuju (TS), (3) : Netral (N), (4) : Setuju (S), (5) : Sangat Setuju (SS) (Supranto, 2011). Analisis yang dilakukan dalam penelitian ini terhadap data yang sudah terkumpul melalui pengisian instrumen kuesioner (data primer) meliputi uji validitas dan reabilitas data, pengujian asumsi klasik (terdiri dari normalitas, multikoinieritas, otokorelasi, heteroskedastisitas), dan analisa regresi berganda.

\section{HASIL DAN PEMBAHASAN}

Penelitian ini berdasarkan pada hasil kuesioner yang telah dibagikan melalui aplikasi online google form (sebanyak 71 kuesioner) dan penyebaran langsung (sebanyak 118 kuesioner). Dari total 189 kuesioner, hanya 171 kuesioner yang memenuhi persyaratan untuk dipakai dalam pengolahan data.

\section{Uji Validitas, Uji Reabilitas, Uji Asumsi Klasik dan Analisa Regresi Berganda}

Berdasarkan hasil uji validitas, diketahui $r$ hitung untuk masing-masing pertanyaan pada variabel uji kualitas produk (X1), kualitas pelayanan (X2), harga (X3) dan kepuasan pelanggan (Y) adalah lebih besar daripada $r$ tabel signifikansi $1 \%$ sehingga dapat disimpulkan pertanyaan yang digunakan untuk pengukuran adalah valid (Santoso, 2016).

Analisis reabilitas menunjukkan nilai cronbach alpha untuk masing-masing variabel adalah 0,911 (X1 - Kualitas Produk), 0,932 (X2 - Kualitas Pelayanan), 0,917 (X3 - Harga), dan 0,903 (Y - Kepuasan Pelanggan). Berdasarkan pengukuran ini, didapat bahwa nilai cronbach alpha adalah lebih besar dari nilai minimal cronbach alpha 0,60 atau dapat dikatakan 
bahwa instrumen penelitian yang digunakan untuk mengukur variabel kualitas produk, kualitas pelayanan, harga dan kepuasan pelanggan adalah reliabel (Santoso, 2016).

Berdasarkan uji asumsi klasik menunjukkan bahwa data terdistribusi normal, tidak terdapat penyimpangan multikolinieritas, tidak terdeteksi masalah otokorelasi dan tidak terjadi masalah heteroskedastisitas.

Persamaan regresi linear berganda pada penelitian ini adalah $Y^{\prime}=-1,049+0,543 \mathrm{X} 1$ + 0,359 X2 + 0,411 X3 (dimana Y' : Kepuasan Pelanggan PT Citra Nusa Insan Cemerlang, X1 : Kualitas Produk, X2 : Kualitas Pelayanan, dan X3 : Harga).

\section{Pengaruh Kualitas Produk terhadap Kepuasan Pelanggan}

Menurut hasil uji t, diketahui bahwa variabel kualitas produk (X1) berpengaruh positif secara langsung dan signifikan terhadap kepuasan pelanggan. Dari ketiga variabel bebas kualitas produk (X1), kualitas pelayanan (X2) dan harga (X3) diketahui bahwa kualitas produk (X1) adalah variabel yang memiliki pengaruh paling dominan dalam menciptakan kepuasan pelanggan. Berdasarkan analisa deskriptif, diketahui bahwa menurut pelanggan produk-produk CNI dengan kategori produk food sudah memiliki kualitas yang baik, ditunjukkan melalui nilai rata-rata skala likert untuk pertanyaan tentang kualitas produk berada pada range 3,84-4,23. Hal ini sesuai dengan karakteristik produk MLM pada umumnya yaitu kualitasnya yang terjamin.

\section{Pengaruh Kualitas Pelayanan terhadap Kepuasan Pelanggan}

Berdasarkan hasil uji t, diketahui bahwa variabel kualitas pelayanan (X2) berpengaruh positif secara langsung dan signifikan terhadap kepuasan pelanggan. Variabel kualitas pelayanan memiliki pengaruh terkecil terhadap kepuasan pelanggan yaitu sebesar 0,359 . Hal ini sesuai dengan perkembangan zaman saat ini bahwa pembelian produk CNI dapat dilakukan melalui aplikasi (gadget) yang sudah terjamin pelayanannya sehingga untuk mencapai kepuasannya, pelanggan lebih berfokus pada kualitas produk dan harga dibandingkan dengan kualitas pelayanan. Berdasarkan analisa deskriptif, diketahui bahwa menurut pelanggan pelayanan CNI sudah memiliki kualitas yang baik, ditunjukkan melalui nilai rata-rata skala likert untuk prameter kualitas pelayanan berkisar dari 3,78-4,12.

\section{Pengaruh Harga terhadap Kepuasan Pelanggan}

Berdasarkan hasil uji t, diketahui bahwa variabel harga (X3) berpengaruh positif secara langsung dan signifikan terhadap kepuasan pelanggan. Dewasa ini di lingkup wilayah Indonesia, harga masih menjadi salah satu pertimbangan dalam kaitannya dengan tingkat kepuasan pelanggan. Hal ini ditunjukkan dari persamaan regresi linear berganda, variabel harga merupakan variabel terpenting kedua setelah kualitas produk dalam konteks pengaruhnya terhadap kepuasan pelanggan. Dari hasil analisa deskriptif, dapat diketahui bahwa menurut pelanggan harga yang ditetapkan pada produk-produk CNI kategori food sudah sesuai. Hal ini ditunjukkan dengan nilai rata-rata skala likert untuk pertanyaan tentang harga berada pada range $3,68-4,01$.

\section{KESIMPULAN}

Berdasarkan hasil penelitian tentang "Studi Pengaruh Kualitas Produk, Kualitas Pelayanan dan Harga terhadap Kepuasan Pelanggan PT. Citra Nusa Insan Cemerlang (CNI) untuk Kategori Produk Food" dapat disimpulkan bahwa:

- Kualitas produk memiliki pengaruh signifikan terhadap kepuasan pelanggan PT Citra Nusa Insan Cemerlang untuk kategori produk food, sebesar 0,543 satuan.

- Kualitas pelayanan memiliki pengaruh signifikan terhadap kepuasan pelanggan PT Citra Nusa Insan Cemerlang untuk kategori produk food, sebesar 0,359 satuan.

- Harga memiliki pengaruh signifikan terhadap kepuasan pelanggan PT Citra Nusa Insan Cemerlang untuk kategori produk food, sebesar 0,411 satuan. 
Kualitas produk (X1), kualitas pelayanan (X2) dan harga (X3) secara simultan berpengaruh signifikan dan positif terhadap kepuasan pelanggan (Y) PT. Citra Nusa Insan Cemerlang untuk kategori produk food.

\section{SARAN}

Adapun saran yang dapat diajukan sebagai masukan adalah sebagai berikut:

1. Bagi PT Citra Nusa Insan Cemerlang (CNI)

Berdasarkan data karakteristik responden untuk parameter usia didapati bahwa 36,8\% responden berusia 41-60 tahun dan diikuti 31,0\% responden berusia 31-40 tahun.Dalam rangka meningkatkan penjualan disarankan untuk menjangkau member baru yang berusia 21-30 tahun (regenerasi) dengan cara membuat produk yang diperuntukkan bagi usia 21-30 tahun seperti produk slimming, produk pangan untuk olahragawan, dan sebagainya.

2. Bagi Akademisi

Untuk meningkatkan koefisien determinasi, maka disarankan bagi peneliti selanjutnya untuk menambah variabel lain yang dapat mempengaruhi kepuasan pelanggan selain variabel kualitas produk, kualitas pelayanan dan harga untuk memenuhi sisa koefisien determinasi sebesar $26,3 \%$.

\section{DAFTAR PUSTAKA}

Axinantio, Yoes. (1996). Multi Level Marketing dan Mail Order. Pekalongan: CV Gunung Mas.

Budiastari, S. (2016). The Influence of Product Quality, Price Perception and Brand Image on Satisfaction and Customer Loyalty Holcim Concrete Readymix in Jakarta. JRMSI Jurnal Riset Manajemen Sains Indonesia 7(2), 345-362. https://doi.org/https://doi.org/10.21009/JRMSI.007.2.08

Farooq, Muhammad S., Salam, M., Fayolle, A., Jaafar, N., Ayupp, K. (2018). Impact of service quality on customer satisfaction in Malaysia airlines: A PLS-SEM approach. Journal of Air Transport Management 67, pp 169-180, DOI: https://doi.org/10.1016/j.jairtraman.2017.12.008.

Iglesias, Marta Pedraja dan Guillen, M. Jesus Yague. (2004). Perceived quality and price: their impact on the satisfaction of restaurant customers. International Journal of Contemporary Hospitality Management, Vol. 16, No.6, pp 373-379, ISSN 0959-6119, DOI: $10.1108 / 09596110410550824$.

Kotler, Philip dan Amstrong, Gary. (2008). Prinsip-Prinsip Pemasaran Jilid 1 dan 2 (edisi 12). Jakarta: Erlangga.

Kotler, Philip and Keller, Kevin Lane (2016). Marketing Management (15 ${ }^{\text {th }}$ ed.). New Jersey: Pearson Education, Inc., publishing as Prentice Hall.

Mudie, Peter dan Pirrie, Angela. (2006). Service Marketing Management ( $3^{\text {rd }}$ ed.). USA: Elsevier.

Roller, David. (1995). Menjadi Kaya dengan Multi Level Marketing. Jakarta: PT Gramedia.

Santoso, Singgih. (2016). Panduan Lengkap SPSS Versi 23. Jakarta: PT Elex Media Komputindo.

Supranto, J (2011). Pengukuran Tingkat Kepuasan Pelanggan untuk Menaikkan Pangsa Pasar. Jakarta: Rineka Cipta.

World Federation of Direct Selling Associations (WFDSA). 2017. World Federation of Direct Selling Associations (WFDSA) record-setting 2016 retail sales of USD 182.6 billion. Accessed $8^{\text {th }}$ April, 2018, from https://wfdsa.org/world-federation-of-direct-sellingassociations-wfdsa-record-setting-2016-retail-sales-of-usd-182-6-billion/.

Zeithaml, Valarie A., Bitner, Mary Jo dan Gremier, Dwayne D. (2009). Services Marketing: Integrating Customer Focus Across The Firm ( $5^{\text {th }}$ ed.) New York: McGraw Hill. 